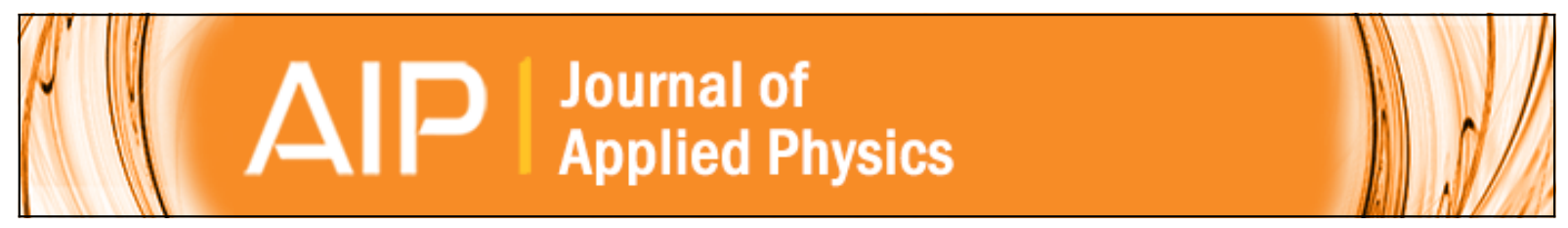

\title{
Glass-forming ability and soft magnetic properties of FeCoSiAIGaPCB amorphous alloys
}

J. M. Borrego, A. Conde, S. Roth, and J. Eckert

Citation: Journal of Applied Physics 92, 2073 (2002); doi: 10.1063/1.1494848

View online: http://dx.doi.org/10.1063/1.1494848

View Table of Contents: http://scitation.aip.org/content/aip/journal/jap/92/4?ver=pdfcov

Published by the AIP Publishing

\section{Articles you may be interested in}

Effects of B and Si contents on glass-forming ability and soft-magnetic properties in ( Co $0.89 \mathrm{Fe} 0.057 \mathrm{Nb} 0.053$ ) $100-x$ ( B 0.8 Si 0.2 ) x glassy alloys

J. Appl. Phys. 107, 09A319 (2010); 10.1063/1.3356233

Soft magnetic powder-core composites of Fe 90 Zr 7 B 3 and Fe 49 Co 21 Al 5 Ga 2 P 9.65 C 5.75 B 4.6 Si 3 alloys

J. Appl. Phys. 99, 08F103 (2006); 10.1063/1.2164413

Mössbauer study of FeCoSiAIGaPCB amorphous alloys

J. Appl. Phys. 95, 4151 (2004); 10.1063/1.1682689

Influence of Si addition on thermal stability and soft magnetic properties for Fe-Al-Ga-P-C-B glassy alloys J. Appl. Phys. 83, 6329 (1998); 10.1063/1.367812

Soft magnetic properties of $\mathrm{Fe}$ based amorphous thick sheets with large glass forming ability

J. Appl. Phys. 81, 4029 (1997); 10.1063/1.364926

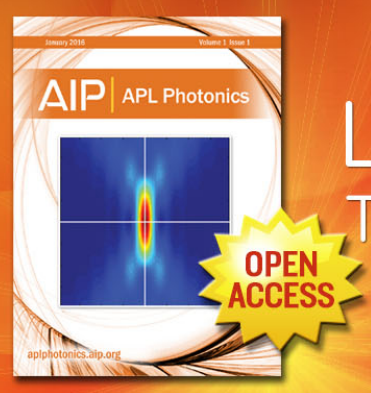

Launching in 2016!

The future of applied photonics research is here 


\title{
Glass-forming ability and soft magnetic properties of FeCoSiAIGaPCB amorphous alloys
}

\author{
J. M. Borrego and A. Conde ${ }^{a}$ \\ Departamento de Física de la Materia Condensada, Instituto de Ciencia de Materiales, CSIC, Universidad \\ de Sevilla, P.O. Box 1065, 41080 Sevilla, Spain
}

S. Roth and J. Eckert

Institut für Metalische Werkstoffe, IFW Dresden, Postfach 270016, D-01171 Dresden, Germany

(Received 21 February 2002; accepted for publication 29 May 2002)

\begin{abstract}
The glass-forming ability of $\left(\mathrm{Fe}_{x} \mathrm{Co}_{y} \mathrm{~B}_{z} \mathrm{C}_{u}\right)_{80} \mathrm{Si}_{3} \mathrm{Al}_{5} \mathrm{Ga}_{2} \mathrm{P}_{10}$ with $x=5-70, y=0-63, z=5-12$, and $u=0-5$ amorphous alloys has been analyzed in terms of the width of the supercooled liquid region, the reduced glass transition temperature, and the Vogel-Fulcher-Tammann parameters. Substitution of Fe by Co slightly decreases the glass-forming ability of the studied alloys. The value of the fragility parameter $m$ is discussed in the frame of the general classification scheme of glass-forming liquids. The crystalline phases formed during the first crystallization step are identified. Magnetic moment at low and room temperature, Curie temperature, room temperature magnetostriction, and coercivity decrease with increasing Co content. (C) 2002 American Institute of Physics.
\end{abstract}

[DOI: $10.1063 / 1.1494848]$

\section{INTRODUCTION}

The development of amorphous soft magnetic materials with a wide supercooled liquid region before crystallization has become an important research topic in recent years. ${ }^{1,2}$ The decrease of the critical cooling rate for glass formation enables the fabrication of bulk amorphous alloys by conventional casting processes and the existence of a wide supercooled liquid region allows for measurements of the thermophysical properties of the undercooled metallic liquid in a broad time and temperature range.,

The glass-forming ability (GFA) of amorphous alloys can be characterized by their critical cooling rate, but this parameter is usually not easy to measure and several other parameters have been used to predict the glass-forming ability of metallic glasses. One of the most widely used is the width of the supercooled liquid region $\Delta T_{x}\left(=T_{x}-T_{g}\right)$, where $T_{g}$ is the glass transition temperature and $T_{x}$ the onset temperature of crystallization of the amorphous alloy. Inoue and Zhang $^{5}$ have stated a close relation between $\Delta T_{x}$ and GFA for a wide variety of bulk glassy alloys: the larger the width of the supercooled liquid region, the lower the critical cooling rate. However, the importance of a chemical decomposition process in the undercooled liquid should be stressed as a key parameter for very good GFA. ${ }^{6}$ The existence of phase separation in the undercooled liquid state was used to explain the disparity between GFA and thermal stability in the alloy series $\mathrm{ZrTiCuNiBe}^{7}$

Based on theoretical work on crystal nucleation in undercooled liquid metals, Turnbull ${ }^{8}$ proposed that the glassforming ability should increase with increasing reduced glass transition temperature $T_{\mathrm{rg}}$ defined as $T_{\mathrm{rg}}=T_{g} / T_{l}\left(T_{l}\right.$ is liqui-

\footnotetext{
a) Author to whom correspondence should be addressed; electronic mail: conde@us.es
}

dus temperature). This correlation has been confirmed in many experiments (see Ref. 9 for a summary).

The study of glass transition kinetics can provide complementary information about the glass-forming ability of the amorphous alloys. It has been found that alloys with high GFA, i.e., low critical cooling rate for glass formation, are stronger metallic glass formers in the "Angell plot" 10 than thermally less stable metallic liquids. ${ }^{11}$ There is only one work about the kinetics of the glass transition of $\mathrm{Fe}$ based alloys with good glass-forming ability. ${ }^{12}$

Amorphous FeSiAlGaPCB alloys are known to have interesting soft magnetic properties combined with good glassforming ability, promising the formation of bulk soft magnetic materials. ${ }^{1,2}$ The replacement of iron by other transition metals may further improve these alloys. In this article, the effect of the substitution of Fe by $\mathrm{Co}$ on the glass-forming ability and the soft magnetic properties of amorphous $\left(\mathrm{Fe}_{x} \mathrm{Co}_{y} \mathrm{~B}_{z} \mathrm{C}_{u}\right)_{80} \mathrm{Si}_{3} \mathrm{Al}_{5} \mathrm{Ga}_{2} \mathrm{P}_{10}$ with $x=5-70, y=0-63, z$ $=5-12$, and $u=0-5$ alloys is reported. The dependence of the glass transition temperature on the heating rate is analyzed in terms of the Vogel-Fulcher-Tammann (VFT) equation, and the value of the fragility parameter $m$ is discussed in the framework of the general classification scheme of glass-forming liquids. ${ }^{10,13}$ The characterization of the crystalline phases formed in the course of the devitrification process was done by means of $\mathrm{X}$-ray diffraction (XRD) measurements.

\section{EXPERIMENT}

Multicomponent alloys with compositions $\left(\mathrm{Fe}_{x} \mathrm{Co}_{y} \mathrm{~B}_{z} \mathrm{C}_{u}\right)_{80} \mathrm{Si}_{3} \mathrm{Al}_{5} \mathrm{Ga}_{2} \mathrm{P}_{10}$ (Table I) were prepared by arc melting under argon atmosphere. Raw materials of high purity were used; metals: $99.99 \%, \mathrm{FeC}$ and $\mathrm{FeB}$ : $99.5 \%$, and FeP: $97.5 \%$. From these alloys, $10 \mathrm{~mm}$ wide and $25 \mu \mathrm{m}$ thick ribbons were prepared by single-roller melt spinning. 
TABLE I. Glass transition temperature $T_{g}$, crystallization onset temperature $T_{x}$, and liquidus temperature $T_{l}$ at $20 \mathrm{~K} / \mathrm{min}$ and Curie temperature $T_{C}$ of $\left(\mathrm{Fe}_{x} \mathrm{Co}_{y} \mathrm{~B}_{z} \mathrm{C}_{u}\right)_{80} \mathrm{Si}_{3} \mathrm{Al}_{5} \mathrm{Ga}_{2} \mathrm{P}_{10}$ alloys.

\begin{tabular}{ccccccc}
\hline \hline Alloy & $\mathrm{A}$ & $\mathrm{B}$ & $\mathrm{C}$ & $\mathrm{D}$ & $\mathrm{E}$ & $\mathrm{F}$ \\
\hline$x$ & 70 & 56 & 43 & 29 & 17 & 5 \\
$y$ & 0 & 14 & 26 & 40 & 52 & 63 \\
$z$ & 5 & 6 & 8 & 9 & 10 & 12 \\
$u$ & 5 & 4 & 3 & 2 & 1 & 0 \\
& & & 762 & 764 & 782 & 790 \\
$T_{g}(\mathrm{~K}) \pm 5$ & 755 & 808 & 808 & 812 & 828 & 828 \\
$T_{x}(\mathrm{~K}) \pm 1$ & 809 & 1300 & 1330 & 1330 & 1320 & 1340 \\
$T_{l}(\mathrm{~K}) \pm 5$ & 1280 & near- & off- & off- & off- & near- \\
Structures & eutectic & eutectic & eutectic & eutectic & eutectic & eutectic \\
$T_{C}(\mathrm{~K}) \pm 3$ & 568 & 554 & 526 & 463 & 373 & 328 \\
\hline \hline
\end{tabular}

The samples were proven to be fully amorphous in the asspun state by XRD measurements. The XRD patterns were recorded at room temperature using a Philips PW 1820 diffractometer with $\mathrm{Co} K_{\alpha}$ radiation. The values of the onset glass transition temperature $T_{g}$, the onset crystallization temperature $T_{x}$, and the crystallization peak temperature $T_{p}$ were determined by differential scanning calorimetry (DSC). The onset glass transition was defined as the point of intersection between the linearly extrapolated curve below the transition with the steepest tangent of the rise in heat flow signal. ${ }^{14}$ The experiments were performed with a PerkinElmer DSC-7 under a continuous argon flow at different heating rates ranging from 2.5 to $160 \mathrm{~K} / \mathrm{min}$. The melting behavior was studied with a Netzsch 404 DSC calorimeter at a heating rate of $20 \mathrm{~K} / \mathrm{min}$. The liquidus temperature $T_{l}$ was determined as the inflection point of the last endotherm of the heating curve (high temperature side).

The magnetization as a function of the temperature $M(T)$ was measured with a Faraday magnetometer in a field of $460 \mathrm{kA} \mathrm{m}^{-1}$. The Curie temperature $T_{C}$ was determined from $M(T)$ curves, fitting the data near $T_{C}$ to a critical law of the form $M(T) \propto\left(T-T_{C}\right)^{\beta}$ with $\beta=0.36$, and extrapolating to $M=0$.

The coercive field $H_{C}$ and the saturation magnetostriction constant $\lambda_{s}$ were measured at room temperature by a Förster Koerzimat and by the small-angle rotation method after Narita ${ }^{15}$ at $15 \mathrm{kA} \mathrm{m}^{-1}$, respectively. The saturation polarization $J_{s}$ at room temperature was measured with a vibrating sample magnetometer, using a maximum field strength of $1500 \mathrm{kA} \mathrm{m}^{-1}$ and at $10 \mathrm{~K}$ with a superconducting quantum interference device magnetometer using an applied magnetic field of $4 \mathrm{MA} \mathrm{m}^{-1}$.

\section{RESULTS AND DISCUSSION}

\section{A. Glass-forming ability and crystallization behavior}

Figure 1 shows the DSC curves for the as-quenched alloys at a heating rate of $20 \mathrm{~K} / \mathrm{min}$. All curves exhibit the endothermic event characteristics of the glass transition, followed by a supercooled liquid region and several exothermic crystallization peaks at higher temperatures. Below the glass transition a wide exothermic event can be observed for all the alloys, which is due to structural relaxation. As shown in Fig. 1 a wide supercooled liquid region can be found for all the compositions. The thermal stability of the amorphous alloys does not show a monotonic dependence on Co content: $T_{x}$ is not affected by Co substitution up to about 26 at. \% Co and shows a small increase of about $20 \mathrm{~K}$ for substitution of more than 52 at. \% Co (Table I). It should be noted that the changes in the $\mathrm{B}$ and $\mathrm{C}$ content (keeping the total metalloid content constant) may also affect this behavior. However, a similar tendency was found for $\mathrm{Fe}_{73.5-x} \mathrm{Co}_{x} \mathrm{Si}_{15.5} \mathrm{~B}_{7} \mathrm{Cu}_{1} \mathrm{Nb}_{3}$ alloys where the $\mathrm{B}$ content was kept constant. ${ }^{16}$ The glass transition temperature increases monotonically as the Co content increases (see Table I). Therefore, the width of the supercooled liquid region $\Delta T_{x}$ slightly increases from 38 to $54 \mathrm{~K}$ as the $\mathrm{Fe}$ content of the alloy increases.

The melting curves of all the alloys at a heating rate of $20 \mathrm{~K} / \mathrm{min}$ are shown in Fig. 2. The curve corresponding to the Co-free alloy (alloy A) exhibits a sharp single melting event, indicative of a eutectic composition. The alloys with the lowest (alloy B) and highest Co content (alloy F) exhibit a melting behavior very near to a eutectic point while the

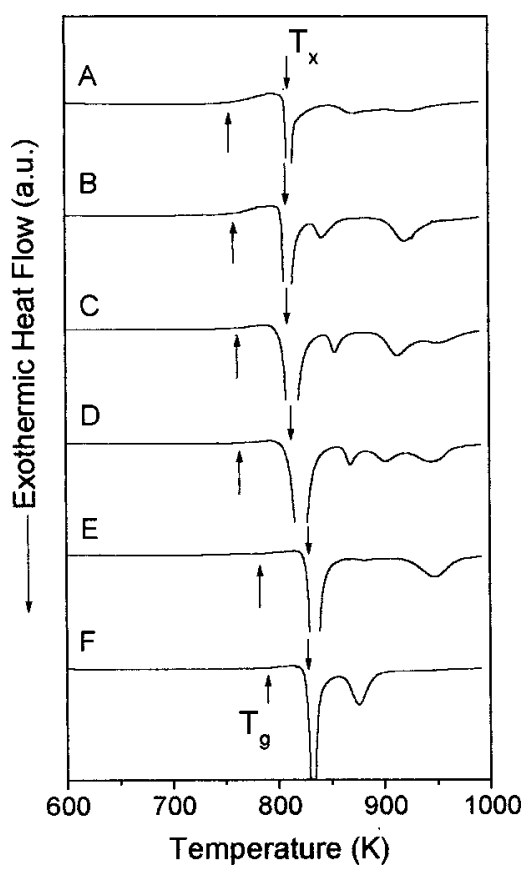

FIG. 1. DSC curves of the as-quenched alloys at a heating rate of $20 \mathrm{~K} / \mathrm{min}$. 


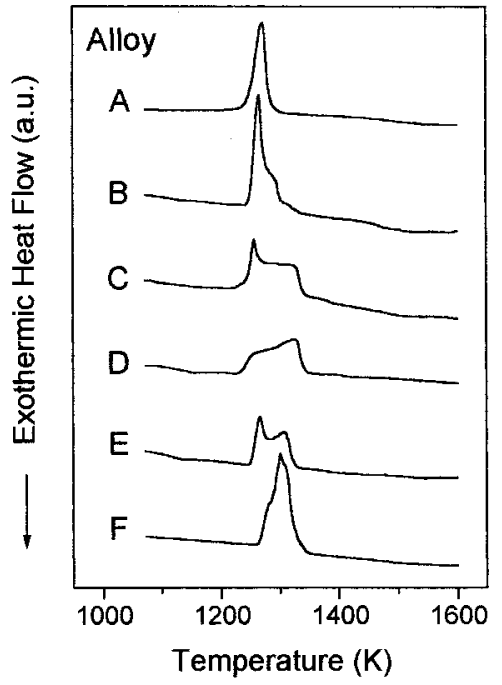

FIG. 2. Melting curves of all the alloys at a heating rate of $20 \mathrm{~K} / \mathrm{min}$.

curves corresponding to the alloys with intermediate compositions (alloys C, D, and E) display two clear melting peaks indicating that they are off eutectic. According to Turnbull's analysis, ${ }^{8}$ a liquid with $T_{\mathrm{rg}} \geqslant 2 / 3$ can only crystallize within a very narrow temperature range, thus can be easily undercooled at a low cooling rate to the glass state. The calculated values of $T_{\mathrm{rg}}$, ranging from 0.57 to 0.59 , are lower than but close to $2 / 3$, reflecting the good glass-forming ability of the present alloys.

The crystallization of the samples occurs in several stages (Fig. 1). The apparent activation energy $E_{a}$, the frequency factor $Z$, and the rate constant of the crystallization process $K_{\text {cr }}$ can be evaluated by using the Kissinger method. ${ }^{17}$ The dependence of the peak temperature $T_{p}$ on the heating rate $\beta$ is described by

$$
\beta / T_{p}^{2}=\left(Z k_{B} / E_{a}\right) \exp \left(-E_{a} / k_{B} T_{p}\right),
$$

where $k_{B}$ is the Boltzman constant and the crystallization rate constant is determined from an Arrhenius law

$$
K_{\mathrm{cr}}(T)=Z \exp \left(-E_{a} / k_{B} T\right) .
$$

The values of the apparent activation energy and the frequency factor found for the first crystallization stage of the studied alloys rise in the same order as the crystallization onset temperature (Table II). The frequency factor $Z$ can be considered as a measure of the probability that an atom having energy $E_{a}$ participates in a crystallization reaction. ${ }^{17}$ The high variation in $Z$ between the alloys with the lowest and the highest Co content could be explained from differences in the crystallization process, i.e., the appearance of new crystalline phases, as will be reported below. Big differences in the value of $Z$ have been also reported for other alloys systems. As an example, in $\mathrm{Zr}_{41} \mathrm{Ti}_{14} \mathrm{Cu}_{12.5} \mathrm{Ni}_{10-x} \mathrm{Fe}_{x} \mathrm{Be}_{22.5}$ $(x=0,2$, and 5$)$ alloys $^{18}$ a substitution of only 5 at. $\%$ of $\mathrm{Ni}$ by $\mathrm{Fe}$ causes a difference in $E_{a}$ of $0.8 \mathrm{eV}$ and in $Z$ of 6 orders of magnitude. A correlation between the value of the rate constant and the width of the supercooled liquid region was found in ZrTiCuNiFeBe (Ref. 18) and FeNbAlGaPCB (Ref. 12) amorphous alloys: the smaller $K_{\mathrm{cr}}$, the larger $\Delta T_{x}$. The opposite tendency is found in the present alloys, for which the rate constant evaluated at the peak temperature $T_{p}$ at 20 $\mathrm{K} / \mathrm{min}$ decreases with increasing Co content, in the same order as $\Delta T_{x}$ (Table II).

The study of the relaxation dynamics of supercooled liquids can be discussed in terms of the fragility, which is the degree of departure from an Arrhenius law of the temperature dependence of a characteristic relaxation time. ${ }^{13}$ The fragility concept is used as the basis for a classification of liquids, to estimate the sensitivity of the liquid structure to temperature changes. ${ }^{10}$ Since viscosity relaxation and the glass transition measured by calorimetric methods occur on the same time scale, the heating rate dependence of the glass transition can be used as a way to determine the fragility of the material. ${ }^{11}$

Prior to the DSC measurements the samples were fully relaxed, as complete relaxation leads to a state that is equivalent to a supercooled liquid, ${ }^{11}$ and which is, therefore, independent of the history of the sample. The conditions of the thermal treatment were chosen in order to get the lowest coercive field: the samples were isothermally annealed at $733 \mathrm{~K}$ (alloys A, B, C, and D), $743 \mathrm{~K}$ (alloy E), and $773 \mathrm{~K}$ (alloy F) for $30 \mathrm{~min}$.

With increasing heating rate, the glass transition temperature shifts to higher temperatures. As an example Fig. 3 shows the curves corresponding to the $\mathrm{Fe}_{70} \mathrm{~B}_{5} \mathrm{C}_{5} \mathrm{Si}_{3} \mathrm{Al}_{5} \mathrm{Ga}_{2} \mathrm{P}_{10}$ alloy (alloy $\mathrm{A}$ ). The dependence of $T_{g}$ on the heating rate $\beta$ given by the VFT equation can be written in the form ${ }^{14}$

$$
\beta\left(T_{g}\right)=B \exp \left\lfloor D T_{g}^{0} /\left(T_{g}^{0}-T_{g}\right)\right\rfloor
$$

where $T_{g}^{0}$ is the asymptotic value of $T_{g}$, usually approximated as the onset of the glass transition in the limit of infinitely slow cooling and heating rate, $B$ has the dimension of a heating rate, and $D$ is the strength parameter.

The fitting of the experimental data was performed using the equation

$$
\ln \beta\left(T_{g}\right)=\ln B-\frac{D T_{g}^{0}}{\left(T_{g}-T_{g}^{0}\right)},
$$

TABLE II. Kissinger parameters. The rate constant $K_{\mathrm{cr}}$ was evaluated at $T=T_{p}$ at $20 \mathrm{~K} / \mathrm{min}$.

\begin{tabular}{ccccccc}
\hline \hline Alloy & $\mathrm{A}$ & $\mathrm{B}$ & $\mathrm{C}$ & $\mathrm{D}$ & $\mathrm{E}$ & $\mathrm{F}$ \\
\hline$E_{a}(\mathrm{eV})$ & $5.4(2)$ & $5.4(2)$ & $5.5(2)$ & $6.0(2)$ & $6.4(2)$ & $7.1(2)$ \\
$Z\left(\mathrm{~s}^{-1}\right)$ & $1(3) \times 10^{32}$ & $1(3) \times 10^{32}$ & $4(3) \times 10^{32}$ & $5(5) \times 10^{35}$ & $1(6) \times 10^{37}$ & $3(9) \times 10^{41}$ \\
$K_{\mathrm{cr}}\left(\mathrm{s}^{-1}\right)$ & $4(2) \times 10^{-2}$ & $4(2) \times 10^{-2}$ & $4(2) \times 10^{-2}$ & $7(2) \times 10^{-3}$ & $2(2) \times 10^{-3}$ & $1(2) \times 10^{-3}$ \\
\hline \hline
\end{tabular}




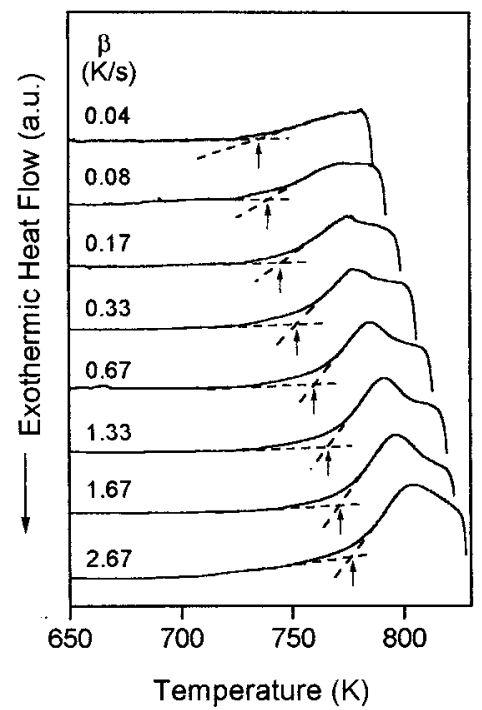

FIG. 3. DSC curves for the alloy $\mathrm{Fe}_{70} \mathrm{~B}_{5} \mathrm{C}_{5} \mathrm{Si}_{3} \mathrm{Al}_{5} \mathrm{Ga}_{2} \mathrm{P}_{10}$ at different heating rates. The arrows indicate $T_{g}$.

with three adjustable VFT parameters: $B, D$, and $T_{g}^{0}$. The calculated values are given in Table III and the best fits are shown by lines in Fig. 4.

The fragility can be quantified by the strength parameter $D$ in Eq. (3), or by the fragility parameter defined as ${ }^{19}$

$$
m=\left.\frac{d \log _{10}\langle\tau\rangle}{d\left(T_{g} / T\right)}\right|_{T=T_{g}},
$$

where $T$ is the temperature, $T_{g}$ the glass transition, and $\langle\tau\rangle$ is the average relaxation time. From the VFT fits the fragility parameter at a particular $T_{g}$ can be calculated from ${ }^{13}$

$$
m=\frac{D T_{g}^{0} T_{g}}{\left(T_{g}-T_{g}^{0}\right)^{2} \ln 10} .
$$

The larger the deviation from an Arrhenius behavior, the larger the value of $m$. The fragility index can be used to classify glass-forming liquids into three general categories: strong, intermediate, and fragile. ${ }^{10}$ Strong liquids with approximately Arrhenius temperature dependence of relaxation times have values of $m$ lower than 30 with an estimated lower limit of $m \approx 16$. In contrast, fragile liquids such as polymers and ionic melts display values of $m$ above 100 .

It should be noted that although the uncertainty of the values of the parameters $T_{g}^{0}, B$, and $D$ is quite high (also pointed out in Ref. 20), changes in the value of $T_{g}^{0}$ result in

TABLE III. Vogel-Fulcher-Tammann parameters for the best fit of the DSC data according to Eq. (4).

\begin{tabular}{cccccc}
\hline \hline Alloy & $\begin{array}{c}\ln B(\mathrm{~K} / \mathrm{s}) \\
\pm 2\end{array}$ & $\begin{array}{c}D \\
\pm 2.0\end{array}$ & $\begin{array}{c}T_{g}^{0}(\mathrm{~K}) \\
\pm 30\end{array}$ & $\begin{array}{c}T_{g} / T_{g}^{0} \\
\pm 0.1\end{array}$ & $\begin{array}{c}m \\
\pm 10\end{array}$ \\
\hline A & 13 & 3.2 & 620 & 1.2 & 34 \\
B & 10 & 1.6 & 660 & 1.2 & 35 \\
C & 8 & 1.3 & 670 & 1.1 & 35 \\
D & 7 & 1.1 & 680 & 1.1 & 35 \\
E & 6 & 0.8 & 710 & 1.1 & 37 \\
F & 5 & 0.5 & 745 & 1.1 & 63 \\
\hline \hline
\end{tabular}

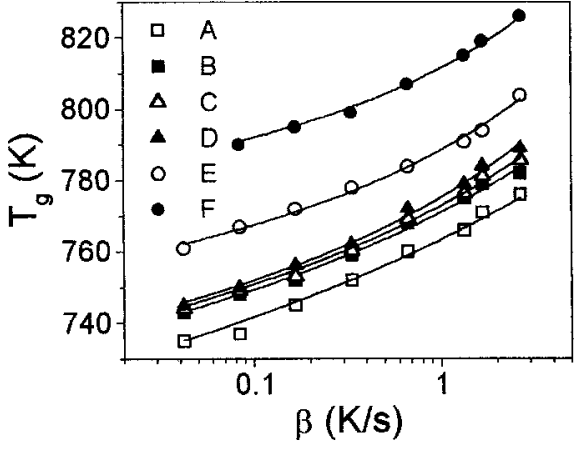

FIG. 4. Glass transition temperature as a function of the heating rate $\beta$ and VFT fit of the data [Eq. (4)].

changes in $D$ that keep the value of $m$ reasonably constant. The obtained values of $D$ are close to those found for FeNbAlGaPCB alloys. ${ }^{12}$ The increase of the lower limit for the glass transition $T_{g}^{0}$ and the decrease of the strength parameter $D$ with increasing Co content point in the same direction as the decrease in the width of the supercooled liquid region. The fragility parameter $m$, evaluated at $T_{g}$ corresponding to a heating rate of $20 \mathrm{~K} / \mathrm{min}$, was found to be around 35 for alloys A, B, C, D, and E, and about 63 for the alloy with the highest Co content (alloy F). This result indicates that these alloys lie in the intermediate category according to Angell's classification scheme, i.e., between the strong and the fragile extremes. A fragility $m$ of about 35 would suggest a very good glass-forming ability, a finding that it is corroborated by the fact that $\mathrm{Fe}-(\mathrm{Al}, \mathrm{Ga})-(\mathrm{P}, \mathrm{C}, \mathrm{B}, \mathrm{Si})$ bulk glassy samples with thickness of $1-15 \mathrm{~mm}$ have been obtained. ${ }^{1}$ Similar values of $m$ have been found in several multicomponent amorphous systems such as $\mathrm{ZrTiCuNiBe}$ and $\mathrm{MgCuY}$ alloys, ${ }^{21}$ which are reported to be excellent metallic glass formers. ${ }^{22,23} \mathrm{~A}$ fragility value of about 60 for the Co richest alloy indicates a lower glass-forming ability for this alloy.

In order to clarify the reason for the good glass-forming ability of these alloys, the crystalline phases formed in the first crystallization stage were analyzed. Figure 5 shows the XRD patterns corresponding to samples of all the alloys annealed at $800 \mathrm{~K}$ for $1 \mathrm{~h}$. The annealed samples A, B, C, and $\mathrm{D}$ present the same crystalline phases: (i) a bcc Fe solid solution containing $\mathrm{Co}$ and $\mathrm{M}$, where $\mathrm{M}$ stands for $\mathrm{P}, \mathrm{C}, \mathrm{Al}$, $\mathrm{B}$, and $\mathrm{Ga}$ elements, with a lattice parameter that decreases as the Fe content of the amorphous alloy decreases, indicating changes in the composition $(a=0.2868 \mathrm{~nm}$ alloy A, $a$ $=0.2857 \mathrm{~nm}$ alloy B; $a=0.2853 \mathrm{~nm}$ alloy C, and $a$ $=0.2852 \mathrm{~nm}$ alloy D); (ii) a phase with a $\mathrm{Ni}_{3} \mathrm{P}$-like tetragonal structure (space group: $I_{4}$ ) and lattice parameters $a$ $=0.893 \mathrm{~nm}$ and $c=0.441 \mathrm{~nm}$ (Ref. 24) and a composition close to $\mathrm{Fe}_{3}(\mathrm{M})$, and (iii) a phase with an $\mathrm{Fe}_{3}(\mathrm{NiN})_{2}$-like cubic structure (space group $P m 3 \mathrm{~m}$ ), with a lattice parameter of about $0.378 \mathrm{~nm}$ (Ref. 24) and a composition close to $\mathrm{Fe}_{3}(\mathrm{M})_{2}$-like cubic structure. The last two phases were previously found in alloys with similar compositions. ${ }^{25}$ The simultaneous crystallization of these three phases causes the crystallization to be retarded, and thus promote a wide supercooled liquid region. The slightly higher crystallization 


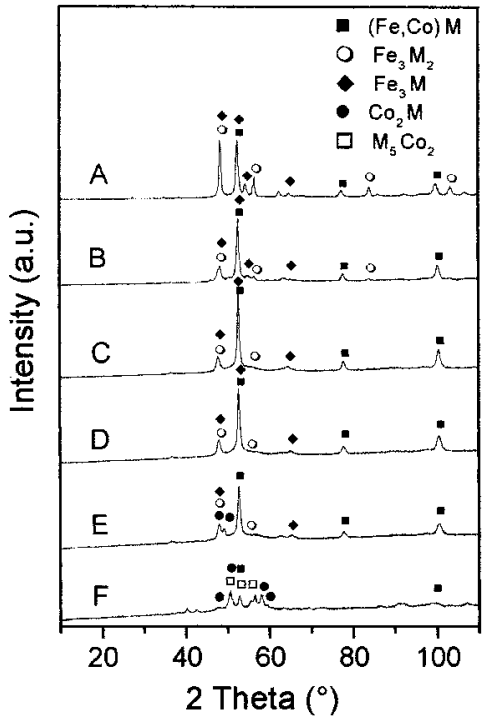

FIG. 5. XRD patterns corresponding to samples of all the alloys annealed at $800 \mathrm{~K}$ for $1 \mathrm{~h}$.

temperature of the Co-richest alloys ( $\mathrm{E}$ and $\mathrm{F}$ ) might be due to the appearance of new Co-rich phases: a phase $\mathrm{Co}_{2} \mathrm{M}$ with an orthorhombic structure (space group Pnam) with lattice parameters $a=0.565 \mathrm{~nm} ; b=0.660 \mathrm{~nm}$, and $c=0.351 \mathrm{~nm}$ (Ref. 24) is found in the two alloys; and (v) a phase $\mathrm{M}_{5} \mathrm{Co}_{2}$ in alloy $\mathrm{F}^{24}$ However, this increase in $T_{x}$ in alloys $\mathrm{E}$ and $\mathrm{F}$ is accompanied by an increase in $T_{g}$ resulting in a final decrease of the width of the supercooled liquid region.

\section{B. Magnetic properties}

The saturation magnetization at 300 and $10 \mathrm{~K}$ of as-cast samples shows a linear dependence on the Fe content [Fig. $6(\mathrm{a})]$ which reflects the substitution of Fe by $\mathrm{Co}$ moments. Similar results are obtained for $\mathrm{Co}_{75-x} \mathrm{Fe}_{x} \mathrm{Si}_{15} \mathrm{~B}_{10}$ amorphous alloys. $^{26}$ The average magnetic moment per magnetic atom $\langle\mu\rangle$ decreases from 1.8 to $0.7 \mu_{B}$ as the Fe content decreases [Fig. 6(b)]. These values are much lower than those reported for crystalline $\mathrm{FeCo}$ alloys ${ }^{27}$ and amorphous $\mathrm{FeCoSiB}$ alloys ${ }^{28}$ with lower metalloid concentration $(\sim 20$ at. $\%)$. The low values of $\langle\mu\rangle$ can be attributed to the decrease of the number of nearest-neighbor magnetic atoms. ${ }^{29}$ Similar results are found for alloys with metalloid content close to 30 at. $\% .^{29,30}$

The Curie temperature $T_{C}$ of the as-quenched alloys decreases monotonically as the Co content in the alloy increases (Table I). This result can be mainly ascribed to the decrease of the exchange interaction between $\mathrm{Co}-\mathrm{Co}$ pairs provoked by the presence of metalloid atoms. ${ }^{29}$ The Curie temperature and the coercive field are affected by structural relaxation processes: ${ }^{31} T_{C}$ increases as the annealing temperature increases and $H_{C}$ decreases monotonically as the relaxation progresses. The lowest coercivity, $H_{C}(\mathrm{~min})$, obtained after annealing the samples for $30 \mathrm{~min}$ at temperatures between 713 and $733 \mathrm{~K}$, decreases as the Co and B content
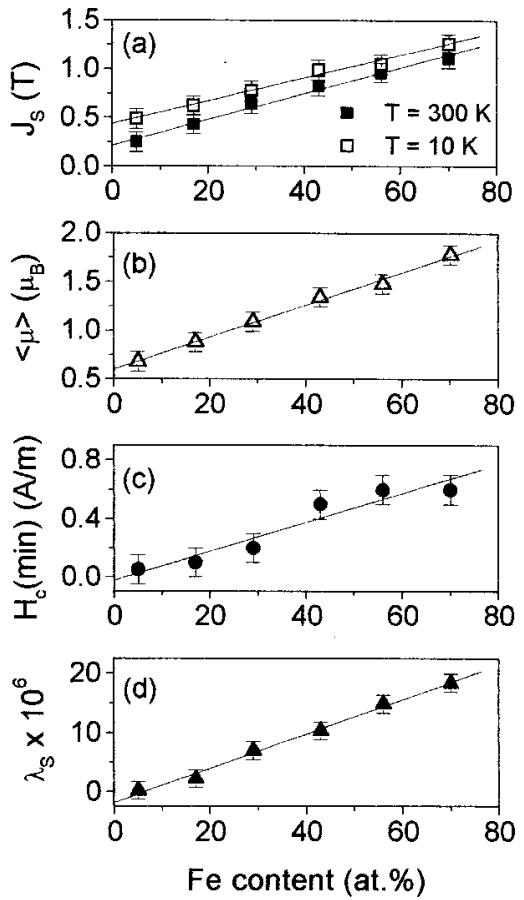

FIG. 6. Saturation magnetization $J_{s}$ at 300 and $10 \mathrm{~K}$ (a); magnetic moment per $(\mathrm{Fe}+\mathrm{Co})$ atom $\langle\mu\rangle$ at $10 \mathrm{~K}(\mathrm{~b})$; minimum coercivity after annealing $H_{C}(\min )(\mathrm{c})$; and saturation magnetostriction constant $\lambda_{s}$ as a function of the Fe content $(d)$.

of the alloy increases [Fig. 6(c)]. This dependence correlates well with that observed for the saturation magnetostriction [Fig. 6(d)].

\section{CONCLUSIONS}

The GFA of $\left(\mathrm{Fe}_{x} \mathrm{Co}_{y} \mathrm{~B}_{z} \mathrm{C}_{u}\right)_{80} \mathrm{Si}_{3} \mathrm{Al}_{5} \mathrm{Ga}_{2} \mathrm{P}_{10}$ amorphous alloys has been analyzed in terms of different parameters, such as the width of the supercooled liquid region, the reduced glass transition temperature, and the VFT fitting parameters. Substitution of $\mathrm{Fe}$ by $\mathrm{Co}$ slightly decreases the GFA. The value of the fragility parameter $m$ indicates that these alloys lie in the intermediate category according to Angell's classification scheme, i.e., between the strong and the fragile extremes. Curie temperature, saturation magnetization, coercivity, and magnetostriction decrease as the Co content increases, the last reaching a nearly zero value.

\section{ACKNOWLEDGMENTS}

The authors thank H. Grahl for the preparation of the samples and N. Mattern and A. Ostwald from IFW Dresden for the XRD measurements and their valuable help for the identification of the crystalline phases. This work was partially supported by the Spanish Ministry of Science and Technology and EU-FEDER (Project Nos. PB97-1119C02-01 and MAT 2001-3175) and by the PAI of the Junta de Andalucía. J.M.B. acknowledges the IFW Dresden and the Junta de Andalucía for research fellowships.

\footnotetext{
${ }^{1}$ A. Inoue, A. Makino, and T. Mizushima, J. Magn. Magn. Mater. 215-216, 246 (2000).

${ }^{2}$ A. Inoue, A. Takeuchi, and B. Shen, Mater. Trans., JIM 42, 970 (2001).
} 
${ }^{3}$ R. Busch, Y. J. Kim, and W. L. Johnson, J. Appl. Phys. 77, 4039 (1995).

${ }^{4}$ U. Geyer, S. Schneider, W. L. Johnson, Y. Qiu, T. A. Tombello, and M. P. Macht, Phys. Rev. Lett. 75, 2364 (1995).

${ }^{5}$ A. Inoue and T. Zhang, J. Non-Cryst. Solids 250-252, 552 (1999).

${ }^{6}$ W. L. Johnson, MRS Bull. 24, 42 (1999).

${ }^{7}$ T. A. Waniuk, J. Schroers, and W. L. Johnson, Appl. Phys. Lett. 78, 1213 (2001).

${ }^{8}$ D. Turnbull, Contemp. Phys. 10, 473 (1969).

${ }^{9}$ Z. P. Lu, H. Tan, Y. Li, and S. C. Ng, Scr. Mater. 42, 667 (2000).

${ }^{10} \mathrm{C}$. A. Angell, Science 267, 1924 (1995).

${ }^{11}$ R. Busch, E. Bakke, and W. L. Johnson, Acta Mater. 46, 4725 (1998).

${ }^{12}$ N. Mitrovic, S. Roth, and J. Eckert, Appl. Phys. Lett. 78, 2145 (2001).

${ }^{13}$ R. Böhmer, K. L. Ngai, C. A. Angell, and D. J. Plazek, J. Chem. Phys. 99, 4201 (1993).

${ }^{14}$ R. Brüning and K. Samwer, Phys. Rev. B 46, 11318 (1992).

${ }^{15}$ K. Narita, J. Yamasaki, and H. Fukunaga, IEEE Trans. Magn. 16, 435 (1980).

${ }^{16}$ M. Müller, H. Grahl, N. Mattern, U. Kühn, and B. Schnell, J. Magn. Magn. Mater. 160, 284 (1996).

${ }^{17}$ H. E. Kissinger, Anal. Chem. 29, 1702 (1957).

${ }^{18}$ Y. X. Zhuang, W. H. Wang, Y. Zhang, M. X. Pan, and D. Q. Zhao, Appl. Phys. Lett. 75, 2392 (1999).

${ }^{19}$ R. Böhmer and C. A. Angell, Phys. Rev. B 45, 10091 (1992).

${ }^{20}$ S. Linderoth, N. H. Pryds, M. Ohnuma, A. S. Pedersen, M. Eldrup, N.
Nishiyama, and A. Inoue, Mater. Sci. Eng., A 304-306, 656 (2001).

${ }^{21}$ D. N. Perera, J. Phys.: Condens. Matter 11, 3807 (1999).

${ }^{22}$ Y. J. Kim, R. Busch, W. L. Johnson, A. J. Rulison, W. K. Rhim, and D. Isheim, Appl. Phys. Lett. 65, 2136 (1994).

${ }^{23}$ A. Inoue, T. Nakamura, N. Nishiyama, and T. Masumoto, Mater. Trans., JIM 33, 937 (1992).

${ }^{24}$ JCPDS cards for the crystalline phases are: $14-212$ for the $\mathrm{Ni}_{3} \mathrm{P}$ structure, 9-318 for the $\mathrm{Fe}_{3}(\mathrm{NiN})_{2}$ structure, 32-306 for $\mathrm{Co}_{2} \mathrm{M}$ structure, and 481301 for $\mathrm{M}_{5} \mathrm{Co}_{2}$ structure. International Center for Diffraction Data, 1601 Park Lane Swarthmore, PA 19081.

${ }^{25}$ J. Z. Jiang, J. S. Olsen, L. Gerward, S. Abdali, J. Eckert, N. Schlorke-de Boer, L. Schultz, J. Truckendrodt, and P. X. Shi, J. Appl. Phys. 87, 2664 (2000).

${ }^{26}$ M. Knobel, R. Sato Turtelli, and R. Grössinger, J. Magn. Magn. Mater. 116, 154 (1992).

${ }^{27}$ D. I. Bardos, J. Appl. Phys. 40, 1371 (1969).

${ }^{28}$ M. Goto, H. Tange, and T. Tokunaga, Jpn. J. Appl. Phys. 17, 1877 (1978).

${ }^{29}$ B. G. Shen, L. Cao, and H. Q. Guo, J. Appl. Phys. 73, 5730 (1993).

${ }^{30}$ K. Narita, J. Yamasaki, and H. Fukunaga, IEEE Trans. Magn. 14, 1016 (1978).

${ }^{31}$ J. M. Borrego, A. Conde, S. Roth, and J. Eckert, J. Magn. Magn. Mater. (in press). 